\title{
On the Application of National Traditional Arts in Modern Graphic Design
}

\author{
Huang $\mathrm{Xu}^{1, \mathrm{a}}$ \\ ${ }^{1}$ Zhang Daqian School of Fine Arts, Neijiang Normal University, 64112 \\ ${ }^{\mathrm{a}}$ email
}

\begin{abstract}
Key Words: National Traditional Arts, Graphic Design, Calligraphy, Chinese Ink Painting, Paper-cut
\end{abstract}
\begin{abstract}
The splendid traditional culture of China is not only our valuable asset, but also a bottomless supply of inspiration for artistic creation. Graphic design is an important component in the visual communication system in modern society. A lot of new elements are crowding into China, which urges the graphic design to be national and artistic, thus to reflect the profound cultural connotation, rich visual effect and omnipresent fancy. The application of national traditional arts in graphic design adapts to the development requirements of The Times. This thesis will discuss the application of national traditional arts in graphic design through the aspects of calligraphy, Chinese ink painting and paper-cut, etc.

A lot of traditional arts, which adhere to labor's emotion and wisdom, came into being during Chinese history of five thousand years. A nation's cultural deposit is implied in these traditional arts and it is our responsibility to give new vitality to them in modern graphic design and to make them much more valuable in current time. The sustainable development of our social economy, culture and art has provided vast space and convenient conditions for the reformation of graphic design. Every designer is facing with the same challenge, that is to comprehensively consider the differences between Chinese and western culture from the perspective of globalization and nationalization and to conduct different selection and combination of different design elements.
\end{abstract}

\section{Relevance between National Traditional Arts and Modern Graphic Design}

National traditional art is a kind of special form of art. Generally, Chinese traditional art has a history of more than one hundred years as well as a fixed set of creation flow. Most of these traditional arts are passed on from generation to generation, enjoying distinctive national and local characteristics and fully reflecting Chinese people's pursuing and love of beauty. Besides the giant influence of western art concept, a great part of the modern graphic design evolves from the Chinese traditional handicraft. Therefore, it is a centuries-old tradition to apply traditional arts in graphic design.

Same as commodities, arts come into being due to human needs. The commercial value, as well as artistic value, can only be reflected after the consumption of human being. National traditional arts roots in daily life of the common people and is close to people's innermost being, and is closely related to people's productive labor. The modern graphic design, however, comes into being for the convenience of publicity and communication, reflecting strong commercial character and possessing novel artistic character. Both graphic design and national traditional arts are closely related to people's real life, and they appear in all links of our life with similar existence form. In the design process, they two have similar creative ideas and aesthetic orientation, and they have the relationship of mutual inheritance, becoming two important developing stages.

\section{Application of Calligraphy}

Chinese calligraphy is the only one in the world which becomes a school of art. It is called the quintessence of oriental art due to its unique structure and various forms of writing, enjoying many amateurs. In Chinese traditional calligraphy system, all forms of calligraphies, including Small Seal Style, Regular Script and the Han Dynasty calligraphy, have their own unique charm. The Chinese unique aesthetic orientation is incisively and vividly reflected in the changing and variation of calligraphy. The application of calligraphy is quite essential in modern graphic design. 
Traditional calligraphy elements have three kinds of conversion in graphic design. The first one is to directly use the element, which means no decoration or change is conducted to the traditional calligraphy and they are directly applied in designs to express the original beauty of calligraphy.

The second one is to conduct some abstract change to the original characters. The viewers' imagination and thought can be motivated by the abstract creation, and the creation itself is out of order and is changing. This kind of method concentrates on casualness and unconsciousness, and the completed work is sometimes bold and unconstrained and sometimes gentle and quite. Currently, the abstract expression of calligraphy in graphic design can be mainly divided into two kinds. One of it emphasizes the innervations and sense of speed, which is full of passion; and the other mainly takes use of the elements of Chinese ink painting, aiming at creating a feeling of dew and indistinct, which is a considerable way of mixing modern graphic design and calligraphy. The viewers can see different things from different perspectives, making the work itself much more figurable.

The third one is selective inherit. The current spiritual wealth of human being is created and accumulated generation after generation. This can be well provided by Chinese calligraphy, which enjoys different expressions in different ages. To go beyond the previous generation, we must learn the ancestors' creation essence. At the present times, the visionary group of graphic designer has found the beauty of Chinese calligraphy and the giant development space of the traditional art. They don't completely copy the tradition of the past when they use the calligraphy art as reference. On the contrary, they develop new things on the modeling and expressions of calligraphy according to their own thoughts. The most well known illustration of this should be the “京” seal during Beijing Olympic Games. The author transformed Chinese traditional seal cutting to embody the spiritual connotation of struggling and fighting in Olympics, and to reveal the deep culture of China as well as the regional characteristics of Beijing. We can see from this example that the Chinese traditional calligraphy is not stable without changes. Only when we inherit and innovate, can we take calligraphy as the element resource or creation and better express the charming of calligraphy in graphic design.

Seen from commercial perspective, the characteristic in package design bears the main information the manufacture want to transitive to the consumers. It is very important for the establishing of brand image and exhibition of cultural deposits. Therefore, calligraphy is always adopted in the package design of products. We can see a lot of examples in daily life. Among all kinds of calligraphy elements, the trademark design is the most visualized and striking. The merchants take advantage of the front side of the package to arrange their brand image calligraphy to impress the consumers. As for the structure and typeface, the designer will conduct corresponding process and change according to different product positioning, thus to strengthen the expressive force of characters. For example, the top grade and expensive products will always choose concise calligraphic style to emphasize characters and leave a lot of space to embody its restraining and elegance. As for the typeface, traditional calligraphy will be chosen as the brand image character to strengthen the decorous feeling of brand history. This kind of design not only emphasizes the national features of product, but it also makes the consumers feel kind and to feel a sense of identity.

\section{Application of Chinese Ink Painting}

Same as calligraphy, ink painting is also a kind of artistic forms which has long history. As for expression, ink painting art emphasizes more on the construction of artistic conception. The white space mode of composition as well as versatile modeling language gives the picture a refined temperament of primitive simplicity. In modern graphic design, the application of ink painting can not only enrich design philosophy, enhance cultural deposit and manifest national spirit, but it can also make the pictures more unique, with distinct expression and great feeling of design.

The application of ink painting in modern graphic design is mainly embodies in picture composition and masstone. First, we will talk about the composition. The composition of ink painting concentrates on the unity and opposition of primary and secondary, contrast, far and near, false and true, fast and slow, 
sparse and intense, open and close, black and white as well as big and small. In the process of design, the designers pay attention to make hard things simple. They appropriately extrude the subject and desalt the object. All the elements in the picture are somewhat connected. The shade of ink painting can not only play a role of contrast, it can also generate the sense of space. If the balance between static and free flowing is just right, the requirement of ink painting can be met. Or, it will be disorderly and unsystematic. The reasonable allocation of parse and intense, as well as open and close can result in an image that delivers rhythm. The color of white is not only a constituent part of the things in pictures, it can also be used to leave "white space" to express the artistic conception of works, leaving the audience with imaginary space. A very good example can be found in modern household advertising. The design of poster emphasizes on the highlighting of subject with contrast of far and near, as well as sparse and intense. The ubiquitous white space enables the consumers with broad imaginary space, making them much more comfortable. It is thus clear that it is feasible to complete graphic design according to the composition concept of ink painting.

Then let's analyze the application of ink color. The most commonly seen ink application modes are light, thick and dense black. Because of its strong mobility and hierarchy, the ink color can be well used to express the shifty things, embodying unique Chinese poise and charm. In real design, the designers will firstly pay attention on the primary and secondary position of ink color. Generally, black is used as the primary color and white the secondary. The black color is used to sketch the outline and form of the subject, and lighter black is used to express the gradation and trend of picture, while the white color is used as the background to set off subject by contrast. In the ink painting-oriented graphic design, we can use very litter colors. Therefore, we must well deal with the change of color to enrich the expressive force of works. Surely we can use other colors although black is taken as the primary color. On the contrary, the other colors can much more easily attract the audiences when they exist in pictures of black and white. Therefore, the designers can boldly use other colors to make the picture much more interesting and vivid on the basis of keeping black and white as the primary color.

\section{Application of Paper-cut}

Chinese paper-cut is of unique style and is one of the most representative forms of art in Chinese folk art. Compares with calligraphy and ink painting, paper-cut is much closer to labors' daily life. It can be said that paper-cut is one of the most important carriers of folk culture, and it is a rare material base of modern art creation.

The unique form and style of paper-cut can be successfully utilized in graphic design in many ways, including image molding, hybrid space-time model method, form-adaptive modeling, imaginary modeling and sound/form unified modeling, etc. The image modeling advocate the philosophical thought of "harmony between yin and yang" and it helps to conduct style design through the positive and negative forms conversion. In hybrid space-time model method, the designers put animals and plants which are in different times and spaces together to show the design of great originality, expressing peoples' understanding and thought of nature. Form-adaptive modeling always takes a specific image as the basis and signifies the images with tricks of increase, deletion, expansion, simplification and exaggeration, ect., to show symmetry and standardized beauty. Imaginary modeling method is to complete the imagination of the object through metaphor and personification. The sound/form unified modeling can also be understood as homophonic method. The designers will comprehensively take advantage of the sound and form to express the common peoples' expectation for good life.

Thanks to its various kinds of composition thoughts, paper-cut can adapt to the influence and impact of different cultures. The current designers should make their works full of cultural deposits. At the same time, they should be able to get paper-cut into graphic design, thus to carry forward the paper-cut art.

\section{Conclusion}

The splendid and colorful Chinese cultural heritage should be treasured by all of us. The profound 
calligraphy, transcendent ink painting and vivid paper-cut art are all important resources of modern graphic design. We should learn the techniques of traditional national art more carefully. Also, we should continuously try to add new things in creation, conclude the creation principle of art and put forward more creation strategy. In today's view of aesthetics, value and cultural progress, modern graphic artists will continue to create better works by combining modern techniques with traditional values on the basis of deep national, cultural foundation. Moving forwards, it is believed that the charm of modern graphic design as well as the cohesion of ethnic cultures will continue to strengthen.

\section{Bibliography:}

[1] Z. Li, Comparison of Calligraphy and Graphic Design [J] Hunan Normal University, 2011 (In Chinese)

[2] X.Y. Hu, Application of Ink Painting in Graphic Design [J], Art Culture, Wen Hai Yi Yuan, 2011 (In Chinese)

[3] T. Shi, Application of Chinese Traditional Elements in Graphic Design [J], Yellow River of the Song, 2010(7). (In Chinese) 